\title{
Synthesis of Some Glycine Nicotinates and in-vivo Evaluation of Anti-Convulsant Activity for their Brain specific Slow Release Action
}

\author{
Kamta P. Namdeo ${ }^{1, \star}$, Sushant K. Shrivastava ${ }^{2}$, Ramesh Chandra ${ }^{3}$ \\ ${ }^{1}$ SLT Institute of Pharmaceutical Sciences, Guru Ghasidas University, Bilaspur, Chhattisgarh, INDIA. \\ ${ }^{2}$ Department of Pharmaceutics, IT BHU, Varanasi, Uttar Pradesh, INDIA. \\ ${ }^{3}$ Department of Chemistry, University of Delhi, New Delhi, INDIA.
}

\begin{abstract}
Aim: Purpose of the present work is to synthesize the pro-pro-drugs of Glycine and evaluate for their anticonvulsant activity in albino rats with brain specific sustained release action in various biological fluids. Materials and Methods: Prepared and synthesized propro-drugs of Glycine nicotinate by esterification with different alcohols and admiration with nicotinic acid. In present work pro-prodrug of Glycine nicotinate were synthesized by taking the Dihydropyridine as carrier molecules. The synthesized compounds have been characterized by IR, IH-NMR, C, H, N analysis and Mass spectral techniques and evaluated for their anticonvulsant activity in albino rats by chemoconvulsion method as well for oxidation in various biological fluids. All the synthesized compounds were found to be active and stable in biological fluids. Oxidized form of the conjugate inside the brain act as pro-pro-drug, which on hydrolysis yields parent drug in sustained release manner. The significance of the work is to treat neurological disorder implicated by Glycine. Results: Pro-pro-drug of Glycine nicotinate were synthesized effectively and showed anticonvulsant activity in slow release manners. Conclusion: This work has given a new synthetic strategy and result of anticonvulsant screening was found encouraging.

Key words: Dihydropyridine, Pro-pro-drug, Nicotinylglycine, Glycine nicotinate, Antiepileptic.
\end{abstract}

\section{INTRODUCTION}

The epilepsy is most common neurological disorder worldwide characterized by unpredictable seizures. In the today's healthcare system epilepsy show greater problem in the population which may due to crippling effects and resultant partial to full invalidity. This abnormal electrical activity may result loss of consciousness, abnormal movements, odd behaviour and distorted perceptions that are of limited duration but recur if untreated. Lack of proper treatment raised the problems. It is better to find for drugs producing potent and better anticonvulsant effects rather than discovery of newer agents due to their well-known side effects along with own metabolism affected by established medications. ${ }^{1}$
Glycine is a major inhibitory neurotransmitter in spinal cord and in brainstem. It has been postulated that glycine produced anticonvulsant activity in brain after metabolism process. The various literature study confirmed that Glycine analogues showed effective action as an anticonvulsant drugs. However, work on the anticonvulsant activity of the various prodrug of Glycine is limited in the literature other than Milacemide. As an extension of work on prodrug Glycine analogues were synthesized for effective treatment of convulsion. ${ }^{2,3}$

The concept of research methods is much more important for increase efficacy and minimise toxicity to explore in the site specific delivery of analogues. Brain specific
Submission Date: 26-07-2020; Revision Date: 02-10-2020; Accepted Date: 14-07-2021

DOI: 10.5530/ijper.55.3.163 Correspondence: Kamta P. Namdeo SLT Institute of Pharmaceutical Sciences, Guru Ghasidas University, Bilaspur, Chhattisgarh, INDIA. Phone:+91999319612 Email: knamdeo@yahoo. com

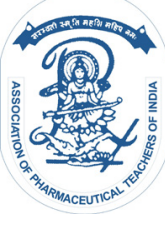

www.ijper.org 
delivery of drugs are restricted by the aspects of transportation and metabolism and more precisely by the highly selective semi permeable border of endothelial cells called blood brain barrier (BBB), the functional barrier. It is established that molecule pass through blood brain barrier depends on partition coefficient of that molecule throughout lipid and water. The approach of prodrug formation by derivatives of parent compounds exhibits enhanced physicochemical properties delivery of the drug in to the brain transport through blood brain barrier. The developing method of Prodrugs approach is totally based on an conversion between Dihydropyridine and pyridinium salt carrier (Dihydropyridine $\rightleftharpoons$ pyridinium salt), similar to the endogenous conversion between nicotinamide adenine dinucleotide hydrogen and nicotinamide adenine dinucleotide $(\mathrm{NADH} \rightleftharpoons \mathrm{NAD}$ ) coenzyme system also called as redox drug delivery system or chemical drug delivery system (CDS). ${ }^{3}$

\section{MATERIALS AND METHODS}

All the chemicals used were commercially procured from Qualigen Mumbai and CDH, New Delhi. All the chemicals and reagents used in the experiment were of analytical grade.

The results are expressed as Mean \pm SEM and results obtained from experiment were subjected to statistical analysis by analysis of variance (ANOVA).

The synthetic procedure of Nicotinyl-Glycine analogues was followed as per the method defined by Bodor et al. ${ }^{3,4}$ (1983) and procedure for synthesis based on four steps as described below.

\section{Step-I: Esterification of Glycine}

1.0 $\mathrm{M}$ of selected alcohol (Methanol, Ethanol, Isopropanol, Butanol and Benzyl alcohol) and $\mathrm{SOCl}_{2}$ $(2 \mathrm{ml}, 0.01 \mathrm{M})$ was taken in a small flask. The mixture was cooled and Glycine $(0.75 \mathrm{~g}, 0.01 \mathrm{M})$ added into it and subjected for reflux for four hours. The solvent was evaporated under vacuum to obtain crude compound. The whole content subjected for trituration at $0^{\circ} \mathrm{C}$ in the presence of ether till excess amount of dimethyl sulphate was removed from the content. The resulting content subjected to dried under vacuum to yield of the ester $\mathrm{HCl}$. The crude ester was recrystallized in $25 \mathrm{ml}$ of hot methanol by gradual addition of $100 \mathrm{ml}$ ether into the above followed by maintaining the temperature at $0^{\circ} \mathrm{C}$.

The crystals obtained from recrystallization were subjected tocollection, washed twicewith solution of Ether and Methanol in the proportion of 5:1, after that washed with ether and kept under high vacuum to dryness ${ }^{5}$. The yield of the methyl, ethyl, isopropyl, butyl and benzyl esters of glycine were found to be 75\%,80\%, 75\%,70\% and $85 \%$ and the melting points were observed at $70^{\circ} \mathrm{C}$, $77^{\circ} \mathrm{C}, 102^{\circ} \mathrm{C}, 124^{\circ} \mathrm{C}$ and $228^{\circ} \mathrm{C}$ respectively.

\section{Step-II: Amidation with carrier molecule}

Ester of glycine $(0.01 \mathrm{M})$ in pyridine $(20 \mathrm{~mL})$ and nicotinic acid $(0.01 \mathrm{M})$ were taken in a round bottom flask. The solution was cooled at $0^{\circ} \mathrm{C}$ followed by solution of dicyclohexylcarba-imide $(2.06 \mathrm{~g}, 0.01 \mathrm{M})$ was added into the mixture and stirred the solution at $20-25^{\circ} \mathrm{C}$ for $24 \mathrm{hrs}$. Dicyclohexyl urea was Precipitated, filtered off the solution and excess solvent was removed with the help of distillation process to get oily residue, which was mixed with $25 \mathrm{ml}$ methylene chloride to precipitate out more dicyclohexyl urea. The resulting residue was collected and crystallized from water at $0^{\circ} \mathrm{C}$ to form crude product. The final compound was isolated by filtration process, dried and recrystallized from 2-propanol. The yield of the N-substituted nicotinyl methyl, ethyl, isopropyl, butyl and benzyl esters of glycine were $90 \%, 95 \%, 85 \%, 90 \%$ and $83 \%$ and the melting points were observed at $240^{\circ} \mathrm{C}, 250^{\circ} \mathrm{C}, 245^{\circ} \mathrm{C}, 260^{\circ} \mathrm{C}$ and $268^{\circ} \mathrm{C}$ respectively.

\section{Step-III: Quaternization of carrier using methyl iodide:}

To a solution of ( 1.0 to $1.37 \mathrm{~g}, 0.005 \mathrm{M})$ product obtained from step-II taken in $10 \mathrm{ml}$ of acetone was added $1.41 \mathrm{~g}(0.01 \mathrm{M})$ methyl iodide. The content was refluxed for six hours with continuous stirring. The Acetone was removed from the contents and residue was recrystallized from methanol. The yield of the esters of $\mathrm{N}$-quaternized nicotinyl glycine were 95\%, 96\%, 89\% $96 \%$ and $91 \%$ with their melting points were $210^{\circ} \mathrm{C}$, $205^{\circ} \mathrm{C}, 200^{\circ} \mathrm{C}, 205^{\circ} \mathrm{C}$, and $170^{\circ} \mathrm{C}$ respectively.

\section{Step-IV: Reduction with sodium dithionite to get 1 , 4-dihydropyridine derivatives:}

To an ice cold solution of $1 \mathrm{~g}(2.5 \mathrm{mmol})$ of compounds esters of $\mathrm{N}$-quaternized nicotinyl glycine obtained from step III, an equal quantity of $200 \mathrm{ml}$ of deaerated water and $200 \mathrm{ml}$ ethyl ether and $1.26 \mathrm{~g}(15 \mathrm{mmol})$ of sodium bicarbonate was added in flask. The content was subjected for continuous stirring for one hour bubbled with the Nitrogen gas. The final mixture was extracted with water $(50 \times 2)$, added anhydrous sodium sulphate for removing water molecule and solvent evaporated to dryness to obtain a compounds. The yield of the compounds (Xf21-Xf25) were 67\%,67\%, 67\%, 50\% and $88 \%$ respectively. The melting points (Xf21-Xf25) are presented in Table 1. 


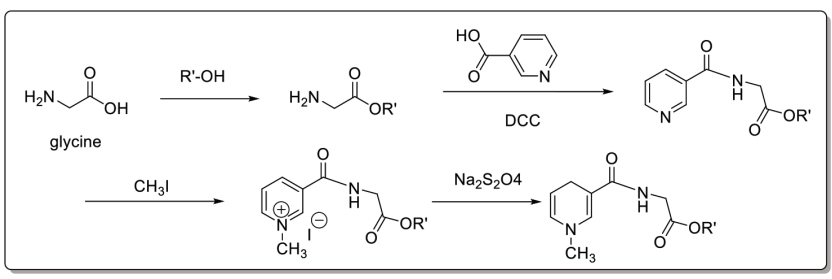

Figure 1: Synthetic pathway

Chemistry: The synthetic reaction pathway is shown in Figure 1.

\section{Physico-Chemical Studies}

Physicochemical properties of the synthesized N-Nicotinyl-Glycine derivatives were confirmed by qualitative chemical screening and thin layer chromatographic technique. Synthesized derivatives gave positive test for Ester and Amide with Nitrogen as an extra element. The melting points of all synthesized compounds were determined by open capillary tubes in liquid paraffin and were uncorrected, presented in Table 1.

Structure elucidation of derivatives were confirmed by modern spectroscopic techniques like UV, IR and NMR and on the basis of $\mathrm{C}, \mathrm{H}$ and $\mathrm{N}$ analysis.

\section{Evaluation}

\section{Experimental Animals}

Healthy albino Wistar rats of either sex (150-260g) were used in present study. The animals were kept under experimental circumstances for seven days before beginning the experiments and allowed food and water as necessary. The animals were maintained under controlled laboratory temperature $\left(27 \pm 2^{\circ} \mathrm{C}\right)$ with $12 \mathrm{hr} / 12 \mathrm{hr}$ light/dark cycle. Before start the experimental protocol initial body weight was measured and recorded.

\section{Acute Toxicity Studies}

The synthesized Pro-pro-drug of Glycine nicotinate derivatives at diverse doses $(50-2000 \mathrm{mg} / \mathrm{kg})$ were administered by oral route to normal rats. Throughout the first four hours and afterward, the oral drug administration gross behavioural changes of animals were observed for 7 days. Parameters of behavioural changes vi\% grooming, hyperactivity, sedation, convulsions, hypothermia, mortality observed for 7 days if any. All derivatives did not show any mortality with oral administration. Even at the highest dose $(2000 \mathrm{mg} / \mathrm{kg})$ for the same. Institutional Animal Ethics Committee (IAEC) had approved the experimental protocol and all the experiments were performed in strict compliance according to ethical guidelines provided by the CPCSEA, Government of India.

\section{Evaluation of Anticonvulsant Activity}

According to experimental protocol the synthesized Nicotinyl-Glycine pro-pro-drugs were evaluated for anti-convulsant activity. The anti-convulsant activity evaluated by the chemo-convulsion method. The convulsions were produced in albino rats by using Strychnine $\mathrm{HCl}$. Healthy albino Wistar rats of either sex $(150-260 \mathrm{~g})$ were used in present research study. The animals were kept under experimental circumstances for seven days before beginning the experiments and allowed food and water as necessary. Before the start of experimental protocol, the animals were fasted overnight without affecting water supply to the rats. The rats were randomly divided into seven groups of six rats each. Control group received with only convulsion producing agent Strychnine $\mathrm{HCl}$. Remaining other group received Strychnine $\mathrm{HCl}$ followed by synthesized compounds (or phenytoin sodium) after 4 hrs. Severity of convulsions of each groups were examined and noted. ${ }^{6,7}$ Anti-convulsant activity of synthesized compounds were compared with the standard drug. Percent of inhibition in convulsion was determined, (Table 1).

\section{Test for Lipophilicity}

Lipophilicity poses a vital role in brain specific drug delivery system. Lipophilicity of the synthesized compounds were calculated by the formula $\mathrm{Rm}=\log$ $\left(1 / R_{f}-1\right)$. Here, the chromatographic $\mathrm{Rm}$ value was associated with penetrating substance in biological cells and calculated $\mathrm{Rm}$ value represents the lipophilicity of these synthesized compounds that were compared to that of respective parent compounds. ${ }^{8,9}$

\section{Test for Oxidation}

The synthesized compounds were subjected for the determination of rate of oxidation in various biological fluids like human blood, brain tissue homogenates, plasma and liver. Oxidation test was performed by preparing methanolic solution of synthesized derivatives into the media. The mixture was kept at $37^{\circ} \mathrm{C}$ and observed in UV spectrophotometer wavelength range from 400-250 $\mathrm{nm}$ for every $10 \mathrm{~min}$ till $2 \mathrm{hrs} .{ }^{10}$ Then percentage of the dihydropyridine derivatives and the quaternary compounds were determined in the biological fluids media and calculated the half lives of these compounds (Table 2). 
Table 1: List of synthesized compounds and anticonvulsants activity.

\begin{tabular}{|c|c|c|c|c|c|c|c|c|}
\hline $\begin{array}{l}\text { Compd } \\
\text { code }\end{array}$ & $\mathbf{R}^{\prime}$ & $\begin{array}{c}\text { M.F. } \\
\text { (m. wt.) }\end{array}$ & $\begin{array}{l}\text { MP } \\
\left({ }^{\circ} \mathrm{C}\right)\end{array}$ & $\begin{array}{l}\text { Avg. wt. } \\
\text { of animal } \\
\text { "g" }\end{array}$ & $\begin{array}{l}\text { Dose } \\
\text { (i.p.) } \\
\mathrm{mg} / \mathrm{kg}\end{array}$ & $\begin{array}{l}\text { "N\%" } \\
\text { Cal./ } \\
\text { found }\end{array}$ & $\begin{array}{c}\text { \%Inhibition } \\
\text { of } \\
\text { Convulsion }\end{array}$ & $\begin{array}{c}\text { Lipophilicity } \\
\text { Rm (Rf) }\end{array}$ \\
\hline$X f 21$ & $\mathrm{CH}_{3}$ & $\mathrm{C}_{10} \mathrm{H}_{14} \mathrm{O}_{3} \mathrm{~N}_{2}(212)$ & 220 & $260 \pm 10$ & 25 & $13.21 / 12.84$ & $60^{*}$ & $2.1(7.8)$ \\
\hline $\mathrm{Xf22}$ & $\mathrm{CH}_{3} \mathrm{CH}_{2}$ & $\mathrm{C}_{11} \mathrm{H}_{16} \mathrm{O}_{3} \mathrm{~N}_{2}(226)$ & 240 & $180 \pm 10$ & 25 & $12.39 / 11.91$ & $40^{*}$ & $1.89(0.013)$ \\
\hline $\mathrm{Xf23}$ & $\left(\mathrm{CH}_{3}\right)_{2} \mathrm{CH}$ & $\mathrm{C}_{12} \mathrm{H}_{18} \mathrm{O}_{3} \mathrm{~N}_{2}(240)$ & 235 & $190 \pm 10$ & 25 & $11.67 / 11.24$ & $80^{* *}$ & $2.44(3.6)$ \\
\hline$X f 24$ & $\mathrm{CH}_{3} \mathrm{CH}_{2} \mathrm{CH}_{2} \mathrm{CH}_{2}$ & $\mathrm{C}_{13} \mathrm{H}_{20} \mathrm{O}_{3} \mathrm{~N}_{2}(254)$ & 240 & $150 \pm 10$ & 25 & $11.02 / 10.99$ & $60^{*}$ & $2.12(7.5)$ \\
\hline Xf25 & $\mathrm{C}_{6} \mathrm{H}_{5} \mathrm{CH}_{2}$ & $\mathrm{C}_{16} \mathrm{H}_{18} \mathrm{O}_{3} \mathrm{~N}_{2}(288)$ & 230 & $240 \pm 10$ & 25 & $9.72 . / 9.69$ & $70^{* *}$ & $2.21(6.1)$ \\
\hline $\begin{array}{c}\text { Phenytoin } \\
\mathrm{Na}\end{array}$ & & & & $190 \pm 10$ & 25 & & 70 & \\
\hline
\end{tabular}

* * Highly significant at $P<0.001$, values are expressed as \pm SEM

* Significant at $P<0.01$.

\begin{tabular}{|c|c|c|c|c|c|c|c|c|}
\hline \multirow[t]{2}{*}{ Compd code } & \multicolumn{2}{|c|}{ Blood } & \multicolumn{2}{|c|}{ Plasma } & \multicolumn{2}{|c|}{ Liver } & \multicolumn{2}{|c|}{ Brain } \\
\hline & $\begin{array}{c}\mathrm{K} \\
\text { “min-1" }\end{array}$ & $\begin{array}{c}\mathbf{t} 1 / 2 \\
\text { "min"-1 }\end{array}$ & $\underset{\text { "min-1" }}{K}$ & $\begin{array}{c}t 1 / 2 \\
\text { "min-1" }\end{array}$ & $\begin{array}{c}\mathrm{K} \\
\text { "min-1" }\end{array}$ & $\begin{array}{c}t^{1 / 2} \\
\text { "min"-1 }\end{array}$ & $\begin{array}{c}\mathrm{K} \\
\text { "min-1" }\end{array}$ & $\begin{array}{c}t 1 / 2 \\
\text { "min-1" }\end{array}$ \\
\hline $\mathrm{Xf21}$ & 0.0492 & 12 & 0.0260 & 26 & 0.301 & 2.3 & 0.133 & 5.2 \\
\hline $\mathrm{Xf22}$ & 0.144 & 4.8 & 0.02887 & 24 & 0.277 & 2.5 & 0.133 & 5.2 \\
\hline $\mathrm{Xf23}$ & 0.0529 & 13.1 & 0.02389 & 29 & 0.1443 & 4.8 & 0.0471 & 14.7 \\
\hline$X f 24$ & 0.144 & 4.8 & 0.0277 & 25 & 0.169 & 4.1 & 0.173 & 4 \\
\hline$X f 25$ & 0.161 & 4.3 & 0.02566 & 27 & 0.169 & 4.1 & 0.144 & 4.8 \\
\hline
\end{tabular}

\section{RESULTS AND DISCUSSION}

All the synthesized compounds revealed a comparable anticonvulsant activity as compared to the standard phenytoin sodium $(25 \mathrm{mg} / \mathrm{kg})$. All synthesized compounds showed a noteworthy $(p<0.01)$ inhibition of convulsion in albino wistar rats induced by Strychnine $\mathrm{HCl}(2 \mathrm{mg} / \mathrm{kg})$ (Table 1 and Figure 2). The synthesized compounds showed $60 \%, 40 \%, 80 \%$, $60 \%$ and $70 \%$ inhibition in convulsion at dose of 25 $\mathrm{mg} / \mathrm{kg}$.

Among synthesized molecules Compounds Xf23 and Xf25 showed high and comparable inhibition of convulsion as compared to standard followed by compounds Xf21, Xf24, and Xf22.

The compound Xf23 showed best activity even better than the standard drugs at dose of $25 \mathrm{mg} / \mathrm{kg}$. The Anticonvulsant activity of another compound Xf25 is comparable to that of standard Phenytoin sodium at dose of $25 \mathrm{mg} / \mathrm{kg}$. and showed almost same duration of action as the standard drug.

All the synthesized compounds were evaluated for lipophilicity using $\mathrm{Rm}$ determination and it showed that all of compounds were capable to cross the blood brain barrier and it was found that lipophilicity of all synthesized compounds were higher as compared to parent drug. The order of most lipophilic to least lipophilic is Xf23>Xf25>Xf24>Xf21>Xf22.

The rate of oxidation of synthesized derivatives were evaluated in various biological fluids and tissue homogenates. All the synthesized compounds showed quite reactivity in these biological fluid media among which compound Xf23 was found to be stable.

However, Xf23 was oxidized in brain homogenate with formation of its pyridinium derivatives $\left(t_{1 / 2}=14.7\right)$. The other dihydropyridine did not show any peripheral toxicity due to lack of any accumulation of corresponding pyridinium compounds in tissues except brain during the incubation period.

Several potential N-Nicotinyl glycine compounds subjected to the Redox Delivery Prodrug Approach (RDPA) to overcome the site specific organ delivery problem. In this experiment the similar methodology has been used for preparing Nicotinyl derivatives 


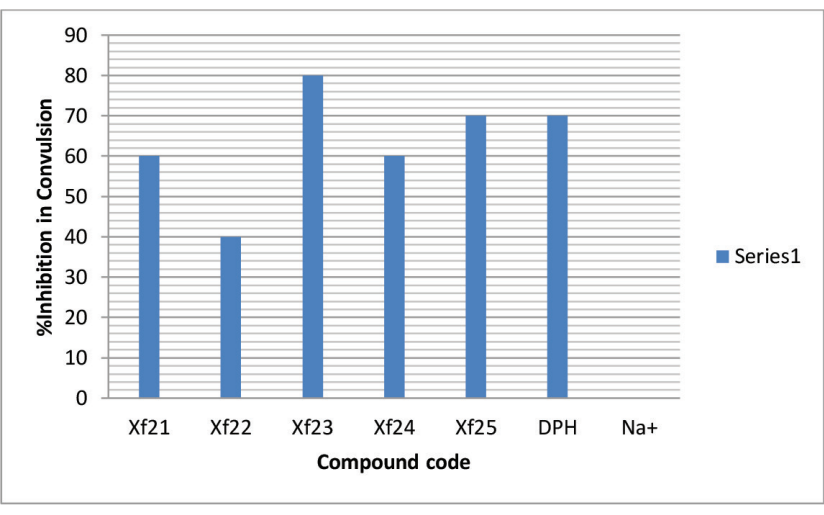

Figure 2: Anticonvusant activity of synthesized compounds.

followed by screening for effective treatment for convulsion and brain targeted specific release.

All the synthesized molecules showed a comparable anticonvulsant activity compared to that of standard phenytoin sodium whereas the compound Xf23 has shown best activity and higher lipophilicity resulting capable to cross the blood brain barrier.

In the rate of oxidation studies it was found that all the synthesized compounds have shown stability in various biological fluids. The in vivo study discloses the administration of dihydropyridine derivative in a sustained manner resulting the presence and absence of quaternary molecule after in blood streams and brain. The synthesized compounds might be showing their anticonvulsant action through glycine agonism ${ }^{11}$ resulting successful reduction of the convulsion induced by Strychnine $\mathrm{HCl}$. These studies revealed that this type of chemical drug delivery System of N-Nicotinyl glycine analogues produced a significant and sustained brain specific anticonvulsant activity by enhancing glycine and inhibit the strychnine $\mathrm{HCl}$ induce excitation.

However further more research work is essential to establish the effectiveness and potency of the synthesized nicotinyl-glycine derivatives as a potent anticonvulsant drugs.

\section{CONCLUSION}

In this study all compounds were synthesized with the specific objective of development of improved anticonvulsant molecules comparable to Milacemide with optimal anticonvulsant activity. From the biological screening result, all the synthesized compounds displayed comparable activity and from that it can be concluded that all of them effective as anticonvulsant against convulsions induced by Strychnine hydrochloride.
The existence of carrier enhances the lipophilicity of drug which support to penetrate the $\mathrm{BBB}$, is required to produce brain specific delivery to inhibit convulsion in minimum dose. From the study it can further concluded that compound substitution with aryl group, has maximal activity as against the compounds substituted with normal alkyl group. It also concluded that compounds substituted with branched alkyl group were more active than the compounds substituted with aromatic group. Among all synthesized molecules compound Xf23 was most effective. Branched carbon atom exhibited significant anticonvulsant activity than the carbon substitution with normal alkyl group.

We established a convenient synthetic method in our experiments for synthesis of new titled compound and outcomes of anticonvulsant screening are encouraging. Further research works with appropriate and rational structural improvement of title compounds may be result in therapeutically beneficial drugs.

\section{ACKNOWLEDGEMENT}

Authors are deeply grateful to the Institute of Pharmacy, Bundelkhand University, Jhansi (U.P.) and Department of Pharmaceutics, Institute of Technology, B.H.U., Varanasi (U.P.) for research facilities.

\section{CONFLICT OF INTEREST}

The authors declare no conflict of interest.

\section{ABBREVIATIONS}

BBB: Blood brain barrier; ROH: Alcohols; DCC: Dicyclohexylcarba-imide; M: Molar.

\section{REFERENCES}

1. Sharma AK, Khosla R, Mehta VL, Kela AK. Antiepileptic agents: Newer generation. Indian J Pharmacol. 1996;28:1-10.

2. Pranzatelli MR, Nadi NS. Mechanism of action of antiepileptic and antimyoclonic drugs. Adv Neurol. 1995;67:329-60. PMID 8848979.

3. Handelmann GE, Nevins ME, Mueller LL, Arnolde SM, Cordi AA. Milacemide, a glycine prodrug, enhances performance of learning tasks in normal and amnestic rodents. Pharmacol Biochem Behav. 1989;34(4):823-8. doi: 10.1016/0091-3057(89)90281-5. PMID 2516327.

4. Bodor N, Farag HH. Improved delivery through biological membranes. 13. Brain-specific delivery of dopamine with a dihydropyridine in equilibrium with pyridinium salt type redox delivery system. J Med Chem. 1983;26(4):528-34. doi: 10.1021/jm00358a013, PMID 6834384.

5. Pop E, Shek E, Murakami T, Bodor NS. Improved anticonvulsant activity of phenytoin by a redox brain delivery system I: synthesis and some properties of the dihydropyridine derivatives. J Pharm Sci. 1989;78(8):609-16. doi: 10.1002/jps.2600780802, PMID 2778665.

6. Webb RG, Haskell MW, Stammer $\mathrm{CH}$. A nuclear magnetic resonance method for distinguishing .alpha.-amino acids from .beta. and .gamma. isomers. J Org Chem. 1969;34(3):576-80. doi: 10.1021/jo01255a020. 
Kulkarni SK. Handbook of experimental pharmacology. 3rd ed Vallabh prakashan. New Delhi; 2004. p. 131-4.

8. Savatore GP, Jose HW, Ewart AS. Effect of stimulus intensity on the profile ofanticonvulsant activity of phenytoin,ethosuximide and valproate. $J$ Pharmacol ExpTher. 1985;232(3):741-5

9. Hansch C, Fujita T. p - $\sigma-\pi$ Analysis. A Method for the Correlation of Biological Activity and Chemical Structure. J Am Chem Soc. 1964;86(8):1616-26. doi: 10.1021/ja01062a035.
10. Fujita T, Iwasa J, Hansch C. A New Substituent Constant, $\pi$, Derived from Partition Coefficients. J Am Chem Soc. 1964;86(23):5175-80. doi: 10.1021/ ja01077a028.

11. Bodor N, Farag HH. Improved delivery through biological membranes. 11. A redox chemical drug-delivery system and its use for brain-specific delivery of phenylethylamine. J Med Chem. 1983;26(3):313-8. doi: 10.1021/ jm00357a002, PMID 6827552.

12. Kadam SS, Mahadik KR, Bothara KG, Principle of medicinal chemistry.10th ed, Nirali prakashan, Pune. 2002;2:224-5.

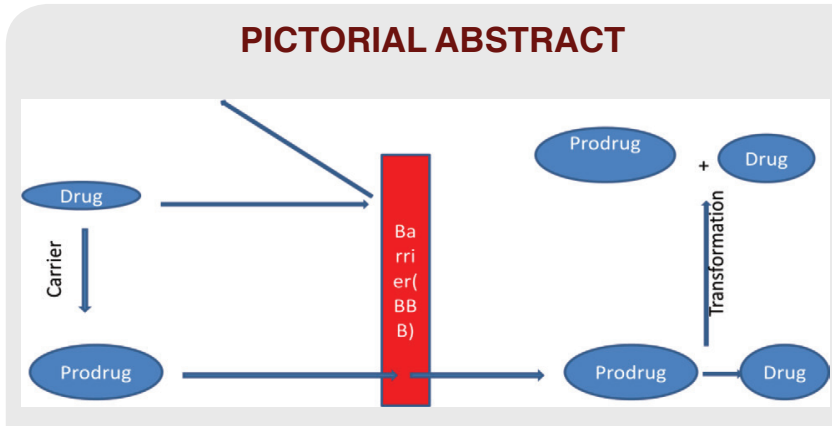

About Authors

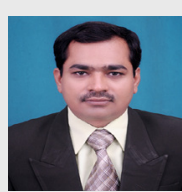

Dr. Kamta P. Namdeo M.Pharm., Ph.D, FIC, Presently working as Associate Professor in Department of Pharmceutical Chemistry, SLT, Institute of Pharma. Sciences Guru Ghasidas Vishwavidhyalya (A Central University) Bilaspur (CG) India. $\mathrm{He}$ has to his credit 24 year of teaching experience.He has published more than 68 reasearch papers and guided $04 \mathrm{Ph}$ D students and 35 M.Pharm. students. $\mathrm{He}$ is the life members of APTI, IPA and Institutions of chemists.

\section{SUMMARY}

In Present work pro-pro-drugs of Glycine nicotinate derivatives were prepared by esterification with different alcohols and amidation with nicotinic acid. In present work pro-pro-drug of Glycine nicotinate were synthesized by taking the Dihydropyridine as carrier molecules. The synthesized compounds were characterized by IR, 1H-NMR, C, H, N analysis and Mass spectral techniques and evaluated for their anticonvulsant activity in albino rats by chemoconvulsion method as well for oxidation in various biological fluids. All the synthesized compounds were found to be active and stable in biological fluids. Oxidized form of the conjugate inside the brain act as pro-pro-drug, which on hydrolysis yields parent drug in sustained release manner. We provided a convenient synthetic method for synthesis a new titled compound and results of anticonvulsant screening are encouraging. Further investigations with appropriate structural modification of title compounds may result in therapeutically useful products.

Cite this article: Namdeo KP, Shrivastava SK, Chandra R. Synthesis of Some Glycine Nicotinates and in-vivo Evaluation of Anti-Convulsant Activityfor their Brainspecific Slow Release Action. Indian J of Pharmaceutical Education and Research. 2021;55(3):888-93. 